\title{
Sustainable Utilization of Plastic Waste in Concrete Mixes - a Review
}

\author{
Kore S. D.*
}

Assistant Professor, Department of Civil Engineering, JSPM Narhe Technical Campus, Pune India

* Corresponding Author: sudarshankore123@gmail.com

Received: 24-05-2018

Revised: $20-10-2018$

Accepted: 21-10-2018

\begin{abstract}
Plastic waste creates serious environmental problems, mainly owing to the inconsistency of the wastes streams. Due to rapid population growth and its consistent necessity the use of plastic is increasing regularly. This creates a large, the quantity of garbage every day which is unhealthy and pollutes the environment. In present scenario solid waste management is a challenge in our country. This paper represents a collection of ideas of various studies done on the use of Plastic Waste Materials in concrete mixes. Conclusions are drawn based upon the respective results of all the mentioned research papers.
\end{abstract}

Key words: Plastic waste, concrete, sustainability.

\section{Introduction}

One of the main goals of sustainable solid waste management is to maximize the ability of its recycling and reusing. The most common waste materials are Metal and plastic which are available in enormous quantities in the world. The modern lifestyle, alongside the advancement of technology has led to an increase in the amount and type of waste being generated, leading to a waste disposal crisis (Jaivignesh and Sofi, 2017). The productive use of waste material represents a means of alleviating some of the problems of solid waste management (Davis and Cornwell, 1998) . Therefore the use of this waste is very important from environment and sustainability aspects. This lead to saving of natural resources and resulting in decrease in environmental pollution. The wastes generated during various operations and their byproduct is one of major problem arising in the world today. Plastic waste is one of the major contributing agent for polluting the environment.

Central pollution control board has estimated the generation of 15,342 tons per day of plastic waste in India. Out of which 9205 tons were reported to be recycled and leaving 6137 tons uncollected (UNEP, 2009). In landfill or in environment plastic bags take up to 1000 years to degrade. The threat due to non-biodegradable materials like waste plastics may contaminate the soil and ground water. Disposal of large quantity of plastic bag may cause pollution of land, water bodies and air. Therefore to reduce these impacts on the environment these materials can be suitably used in other industries (Hassani et al., 2005).

Concrete is one of the commonly and widely used construction material in the world (Sudarshan and Vyas, 2017). To reduce the burden on environment concrete industry conduct a lot of experiments to utilize these waste (Singh et al., 2016). Reuse of solid waste as partial replacement of aggregate in construction activities results in reducing the demand for extraction of natural raw materials as well as saving landfill space. Thus utilization of plastic waste in concrete mixes reduces the demand of natural resources and as a result leads to sustainable development. 


\section{State of Art}

A study carried out by Kou et al. (2009) revealed that: the workability, the compressive strength, and the tensile splitting strength of lightweight aggregate concretes that are prepared with recycled plastic waste were reduced. Ghernouti et al. (2009) conducted a study on concrete mixes with the utilization of plastic waste as replacement of fine aggregate in different percentages $10 \%, 20 \%, 30 \%$ and $40 \%$. It was reported that, the workability of concrete increased with increase in replacement of plastic waste this was due to plastic waste does not absorb water and excess water is available for lubrication. Also, the bulk density decreases with increase of plastic bags waste. In case of flexural and compressive strength, appreciable reductions were observed. Plastic waste increases the volume of voids in concrete which on other hand reduce the compactness of concrete simultaneously speed of sound in concrete is also decreased. Strength reduction in concrete mix was prime concern and however they recommend $10 \%$ to $20 \%$ replacement of fine aggregate with plastic aggregate.

Ismail and Al-Hashmi (2010) studied the effect of replacement of fine aggregate by $5 \%$ plastic waste and $30 \%, 40 \%, 50 \%$ iron fillings on mechanical properties of concrete mixes. In their study they investigated that, at all replacement levels decline in the slump was reported. This fact was attributed to heterogeneous distribution of waste material as well as the sharp and angular grain shapes of the waste particles compared to that of sand. The fresh and hardened density of concrete mixes prepared with iron filling and plastic waste showed increasing trend due to high density of waste iron. From the results of compressive strength it was reported that, the replacement of fine aggregate by iron filing and plastic waste improves the compressive strength by approximately $6 \%, 10 \%$ and $22 \%$ as compared to that of control mixes. This increase in strength was caused by the addition of polymeric material which leads to formation of polymer film during hydration resulting in co-matrix during which polymer is amalgamated with cement hydrate (Van Gemert et al., 2005). Raghatate (2012) studied the feasibility of incorporation of plastic bags in concrete mixes in different percentages $0.2 \%, 0.4 \%, 0.6 \%, 0.8 \%$ and $1.0 \%$. They reported that, incorporation of plastic bags in concrete reduces the compressive strength and tensile strength. But the reduction in strength was within $10 \%$ and it is acceptable as per BIS 456-2000. They finally concluded that, more and detailed study is required to understand the behavior of concrete mix with the addition of plastic bags.

Other study conducted by Mathew et al. (2013) reported the feasibility of utilization of plastic waste as a replacement for natural coarse aggregate in concrete mixes. The plastic coarse aggregate was obtained by crushing the boulder of plastic into the crusher. The concrete mixes was prepared with $20 \%$ to $100 \%$ replacement level with an increment of $20 \%$. They reported that, the replacement of natural coarse aggregate by plastic aggregate enhances the compressive strength of concrete by approximately $10 \%$ at a replacement of $20 \%$ as compared to that of control concrete. As the percentage of replacement increased the concrete mixes showed loss in compressive strength. The decrease in strength was due to less specific gravity and crushing value as compared to that of natural aggregates.

Khilesh (2014) studied the impact of use of plastic waste and steel fiber addition on the properties of concrete. The fine aggregate was replaced by plastic waste at $0.2 \%, 0.4 \%, 0.6 \%$, $0.8 \%$ and $1 \%$ by weight of cement and $0.1 \%, 0.2 \%, 0.3 \% 0.4 \%$ and $0.5 \%$ steel fibers were incorporated in concrete mixes. They observed that, replacement of fine aggregate by plastic waste in different percentages showed an increase in compressive strength whereas marginal reduction in slump as compared to that of control mix. On the other hand the mixture proportion of steel fiber and plastic waste also showed the same trend in compressive strength test. $\mathrm{He}$ summed up that, it was possible to use this plastic waste and steel fiber in concrete to produce a sustainable product.

Subramani and Pugal (2015) reported that, the use of plastic waste as a replacement for conventional coarse aggregate improves the physical and mechanical properties of concrete 
mixes. It was reported that, the compressive strength, flexural strength and split tensile strength of concrete was increased by $8 \%, 5 \%$ and $3 \%$ as compared to that of control concrete at $15 \%$ replacement level. As the percentage of replacement increased beyond $15 \%$ all the properties of concrete showed downward trend. This fact was due to excess presence of water in the concrete mix because plastic waste has very low water absorption as compared to that of conventional coarse aggregate.

Chen et al. (2015) investigated the influence of plastic waste as a fine aggregate on concrete mixes. Fine aggregate was replaced by plastic waste in different percentages $0 \%, 10 \%, 20 \%$, $30 \%, 50 \%$ and $100 \%$. They reported that, at $10 \%$ replacement level only $15 \%$ loss in strength was observed where as in other replacement level a notable reduction was observed as compared to that of control concrete mix. Where as in case of tensile test, the concrete mixes prepared with 10\%, 20\% and 30\% replacement level showed significant increase in the tensile strength of concrete mixes as compared to that of control mix. This increase in tensile strength was attributed due to addition of High-density polyethylene (HDPE) plastic which cause fundamental changes in the concrete. Plastic is a byproduct of the shredding and pulverizing process which provides internal shear and tensile reinforcement. They also stated that, behavior of plastic is alike to that of the synthetic fiber which restricts the propagation of cracks and fractures in the concrete. They also reported that, the heat absorption and heat transfer of concrete modified with $10 \%, 20 \%$ and $30 \%$ replacement showed a significant decrease in heat absorption, and a minor decrease in heat transfer through the test slab.

Ahmed \& Raju (2015) conducted a study on the use of plastic waste as replacement for conventional coarse aggregate (at 10\%) in concrete mixes with different water-cement ratios. They reported that, the workability and the dry density of concrete mixes prepared with plastic waste aggregate were reduced marginally. Harini and Ramana (2015) studied the influence of replacement of plastic waste and silica fume as fine aggregate and cement respectively in concrete mixes. The plastic waste was replaced in the percentage 5\%,6\%, 8\%, 10\%, 15\%, 20\% by volume and silica fume $5 \%, 10 \%, 15 \%$ by weight in concrete. They reported that, the degree of workability was high in all the replacement levels. It was also stated that, in all the replacement levels of plastic waste as fine aggregate showed marginal reduction approximately $10 \%$ in compressive strength as compared to that of control mix. In case of silica fume replacement the compressive strength of concrete mixes increased by $13 \%, 20 \%$ and $23 \%$ at $5 \%, 10 \%$ and $15 \%$ respectively. Tensile strength of concrete reduced marginally at $8 \%$ to $20 \%$ replacement and increased marginally at 5\% and $6 \%$ replacement levels as compared to that of control mix.

In a study conducted by Aravind and John (2015) used crumb rubber and plastic waste as replacement for fine aggregate in concrete mixes with a percentage of 5\%,10\% and 15\%. They reported that, replacement of fine aggregate by crumb rubber and plastic waste in concrete reduces the workability of concrete due to variation in water absorption of the aggregates used. They also reported that, the mechanical properties of concrete such as compressive strength, split tensile strength and flexural strength was maximum at $5 \%$ replacement levels as compared to that of control concrete mix. At $10 \%$ and 15\% replacement level the concrete prepared with plastic waste and crumb rubber as fine aggregate showed downward trend for all the values of strength as compared to that of control concrete mix. A combination of $5 \%$ crumb rubber and $10 \%$ plastic waste as fine aggregate showed lowest rate of water absorption as compared to all other concrete mixes. Finely they concluded that, the optimum percentage for replacement of crumb rubber and plastic waste as fine aggregate in concrete was $10 \%$ for sustainability point of view.

Polyethylene terephthalate (PET) is most and common widely used plastics for soft-drink and packaging of food and other consumer goods (Islam et al., 2016). It is estimated that, words annual consumption of PET drink is approximately 10 million tons and this number increase 
every year by $15 \%$ as reported by Frigione (2010). In particular recycled polyethylene terephthalate (PET), a packing material byproduct, was used as binder in the production of highperformance composite known as polymer concrete (Marzouk et al. 2007). Past researchers showed that, it is possible to use the PET ot plastic waste as construction material in concrete mixes. Guendouz et al. (2016) investigated the impact of waste plastic [(Polyethylene Terephthalate (PET) and Low Density Polyethylene (LDPE)] as a fibers and fine aggregates (powder) in sand concrete. The sand was replaced by plastic aggregates by volume fractions of sand $(10 \%, 20 \%, 30 \%$ and $40 \%)$ and plastic fibers $(0.5 \%, 1 \%, 1.5 \%, 2 \%)$ were introduced by volume in sand concrete mixes. It was reported that, the use of plastic waste as fine aggregate in concrete increases the workability by about $40 \%$. This is probably due to the presence of more free water in the mixes containing plastic, on the other hand incorporation of plastic fibers in concrete reduces the workability. Also the reduction in bulk density and air content was reported. They also reported that, compressive and flexural strengths of concrete prepared with plastic waste as fine aggregate increased by approximately $30 \%$ with $20 \%$ replacement and in case of concrete with plastic fibers it increased by $25 \%$ at $1.5 \%$ content. The authors have concluded that, the optimum percentage for replacement was $20 \%$ and $1.5 \%$ for plastic powder (LDPP) and plastic fibers respectively.

Mahesh et al. (2016) studied the behavior of concrete with the utilization of plastic waste as replacement for fine aggregate in concrete with $2 \%, 4 \%$ and $6 \%$ pulverized/non pulverized polyethylene material. They reported that, at all replacement levels the concrete prepare with plastic waste as fine aggregate showed marginal reduction (less than 10\%) in compressive and split tensile strength as compared to that of control concrete. Authors have concluded that, the use of plastic waste as a replacement for fine aggregate in concrete did not have any adverse impact on mechanical properties of concrete.

Jibrael and Peter (2016) studied the mechanical properties of concrete modified by recycled plastic waste as a partial replacement of fine aggregate $1 \%, 3 \%$ and $5 \%$ by weight. Two types of plastic waste were used, waste plastic bottle and bags for the production of fine aggregate. They observed that, the compressive strength, indirect tensile strength and modulus of rupture decreased when the replacement levels increased. The marginal reduction in all the values of strength was reported at a replacement level of $1 \%$ as compared to that of control mix. At $3 \%$ and 5\% replacement level, the compressive strength, tensile strength and modulus of rupture of concrete prepared with plastic waste as fine aggregate showed average reduction of $16 \%, 27 \%$ and $27 \%$ as compared to that of control concrete. Gaur et al., (2017) studied the impact of plastic waste as a replacement for fine aggregate at 5\%,10\%, 15\%, $25 \%$ by weight in concrete with incorporation of steel fibers $1 \%$ by volume. Due to utilization of steel fibers the reduction in workability was observed. It was stated that, the use of plastic waste as fine aggregate results in reduction in compressive strength at all replacement levels as compared to control concrete mix. Finally they stated that at $5 \%$ replacement levels the compressive strength was nearly close to that of control mix and this proportion was suggested as an optimum proportion for the replacement in concrete mixes.

Mechanical properties of concrete prepared with plastic waste as a replacement of fine and coarse aggregate at 10\%, 15\%, 20\% and 15\%, 20\%, 25\% was studied by Jaivignesh and Sofi (2017). In their study they reported that, the compressive strength of concrete was reduced by $9 \%$ at $10 \%$ replacement level where as at $15 \%$ and $20 \%$ replacement levels the compressive strength was reduced by $13 \%$ and $17 \%$ respectively as compared to that of control concrete mix. A similar trend was observed in split tensile strength and flexural strength test. They concluded that, this reduction in strength is mainly due to poor bond strength between cement and plastic aggregate. This fact was also reported by various researchers in the past.

Ismail \& AL-Hashmi (2008) used the plastic waste as partial replacement $10 \%, 15 \%$ and $20 \%$ for fine aggregate in concrete mixes and studied the mechanical properties of concrete. It was 
reported that, the slump values of concrete modified with plastic waste as fine aggregate were reduced by $68 \%, 88 \%$ and $95 \%$ at $10 \%, 15 \%$ and $20 \%$ replacement levels as compared to that of control mix. This reduction was due to irregular size and shape of aggregate which resulted in less fluidity. The fresh and dry density of concrete mixes prepared with plastic waste at above said replacement levels showed downward trend due to low density of plastic waste. The concrete prepared with plastic waste as replacement for fine aggregate showed reduction in compressive and flexural strength because of decrease in adhesive strength between the surface of the waste plastic and the cement paste. They also stated that, this reduction was due to hydrophobic property of plastic material which restricts the water required for the hydration during the curing period. From the load-deflection curves they reported that, the incorporation of plastic waste restrict the propagation of micro-cracks. They concluded that, all the values of concrete prepared with plastic waste as fine aggregate are higher that required for structural concrete B.S.1881, part 7.

\section{Conclusion}

Based on the above studies on use of plastic waste it can be concluded that:

- The utilization of $10 \%$ plastic waste as fine aggregate replacement gives satisfactory performance in concrete, which results in reduction cost of natural resources.

- The use of plastic waste as replacement for fine aggregate maintains the mechanical properties of concrete.

- The aggregate produced form plastic waste showed an improvement in the workability of concrete mixes where as some of the researchers reported the contradictory results.

Various researchers proposed economy in concrete production can be achieved by utilization of this plastic waste as fine aggregate. The studies reported by researchers, the various types of plastic waste were crushed to obtain desired gradation of fine aggregate and used in concrete mixes. When these plastic waste aggregates are used in concrete mixes as replacement for conventional fine aggregate, showed no adverse effects on quality of concrete but in turn enhanced to some extent the some mechanical performance of concrete.

From the above studies, utilization of plastic waste achieved economy in concrete production with conserving natural resources as well as reduction in environmental hazards reported due to uncontrolled dumping of plastic waste.

\section{References}

Ahmed, M.M. \& Raju, S.S., (2015). Use of Waste Plastic in the Production of Light Weight Concrete. International Journal \& Magazine of Engineering, Technology, Management and Research, 2(April) 365-369.

Aravind, S. \& John, E., (2015). Replacement of Fine Aggregate by Crumb Rubber and Plastic Fines. International Journal of Engineering Research \& Technology (IJERT), 4(11),305-310.

Chen, C.C., Jaffe, N., Koppitz, M., Weimer, W., Polocoser A., (2015). Concrete mixture with plastic as fine aggregate. International Journal of Advances in Mechanical and Civil Engineering, 2(4), 49-53.

Davis, M.L., Cornwell, D.A. (1998). Introduction to Environmental Engineering Third. WCB, ed., McGrawHill.

Frigione, M. (2010). Recycling of PET bottles as fine aggregate in concrete. Waste management, 30(6), 1101-1106.

Gaur, K., Arya, Jyotsana, A.K. \& Singh, N.K. (2017). Use of Plastic as Partial Replacement of Fine Aggregate in Fibre Reinforced Concrete. IOSR Journal of Mechanical and Civil Engineering, 14(3), 71-74.

Ghernouti, Y., Rabehi, B., Safi, B. \& Chaid, R. (2009). Use of recycled plastic bag waste in the concrete Journal of International Scientific Publications: Materials, Methods and Technologies, 8, 480-487. 
Guendouz, M., Debieb, F., Boukendakdji, O., Kadri, E. H., Bentchikou, M., \& Soualhi, H. (2016). Use of plastic waste in sand concrete. J. Mater. Environ. Sci, 7(2), 382-389.

Harini, B. \& Ramana, K. V. (2015). Use of Recycled Plastic Waste as Partial Replacement for Fine Aggregate in Concrete. International Journal of Innovative Research in Science, Engineering and Technology, 4(9), 8596-8603.

Hassani, A., Ganjidoust, H., Maghanaki, A.A. (2005). Use of plastic waste (poly-ethylene terephthalate) in asphalt concrete mixture as aggregate replacement. Waste Management \& Research, 23, 322-327.

Islam, M. J., Meherier, M. S., \& Islam, A. R. (2016). Effects of waste PET as coarse aggregate on the fresh and harden properties of concrete. Construction and Building Materials, 125, 946-951.

Ismail, Z. Z., \& Al-Hashmi, E. A. (2010). Validation of using mixed iron and plastic wastes in concrete. In Second International Conference on Sustainable Construction Materials and Technologies. Ancona (pp. 393-403).

Ismail, Z.Z. \& AL-Hashmi, E.A. (2008). Use of waste plastic in concrete mixture as aggregate replacement. Waste Management, 28(11), 2041-2047.

Jaivignesh, B., \& Sofi, A. (2017). Study on Mechanical Properties of Concrete Using Plastic Waste as an Aggregate. In IOP Conference Series: Earth and Environmental Science (Vol. 80, No. 1, p. 012016). IOP Publishing..

Jibrael, M.A. \& Peter, F. (2016). Strength and Behavior of Concrete Contains Waste Plastic. Journal of Ecosystem \& Ecography, 6(2), 2-5.

Khilesh S. (2014). Study of Strength Property of Concrete Using Waste Plastics and Steel Fiber. The International Journal of Engineering And Science, 3(5), 9-11.

Kou, S. C., Lee, G., Poon, C. S., \& Lai, W. L. (2009). Properties of lightweight aggregate concrete prepared with PVC granules derived from scraped PVC pipes. Waste Management, 29(2), 621-628.

Mahesh, M., Rao, B.V.N. \& Sri, C.H.S. (2016). Re-Use of Polyethylene Plastic Waste In Concrete. International Journal of Engineering Development and Research, 4(4), 693-702.

Marzouk, O.Y., Dheilly, R.M. \& Queneudec, M., (2007). Valorization of post-consumer waste plastic in cementitious concrete composites. Waste Management, 27(2), 310-318.

Mathew, P., Varghese, S., Paul, T., \& Varghese, E. (2013). Recycled plastics as coarse aggregate for structural concrete. International Journal of Innovative Research in Science, Engineering and Technology, 2(3), 687-690.

Raghatate Atul, M. (2012). Use of plastic in a concrete to improve its properties. International journal of advanced engineering research and studies, 1(3), 109-111.

Singh, S., Nagar, R., Agrawal, V., Rana, A., \& Tiwari, A. (2016). Sustainable utilization of granite cutting waste in high strength concrete. Journal of Cleaner Production, 116, 223-235.

Subramani, T., \& Pugal, V. K. (2015). Experimental Study On Plastic Waste As A Coarse Aggregate For Structural Concrete. International Journal of Application or Innovation in Engineering \& Management (IJAIEM), 4(5), 144-152.

Sudarshan, D. K., \& Vyas, A. K. (2017). Impact of fire on mechanical properties of concrete containing marble waste.Journal of King Saud University-Engineering Sciences. Available at: http://dx.doi.org/10.1016/i.jksues.2017.03.007.

UNEP (2009). Converting waste plastics into a resource, United Nations Environment Program Industry and Economics, Osaka/Shi.

Van Gemert, D., Czarnecki, L., Maultzsch, M., Schorn, H., Beeldens, A., Łukowski, P., \& Knapen, E. (2005). Cement concrete and concrete-polymer composites: Two merging worlds: A report from 11th ICPIC Congress in Berlin, 2004. Cement and Concrete Composites, 27(9-10), 926-933. 